\title{
CELL SIZE, NUCLEAR SIZE AND THE NUCLEO-CYTO- PLASMIC RELATION DURING THE LIFE OF A PEDIGREED RACE OF OXYTRICHA FALLAX
}

LORANDE LOSS WOODRUFF

Sheffield Biological Laboratory, Yale University

ONE FIGURE

CONTENTS

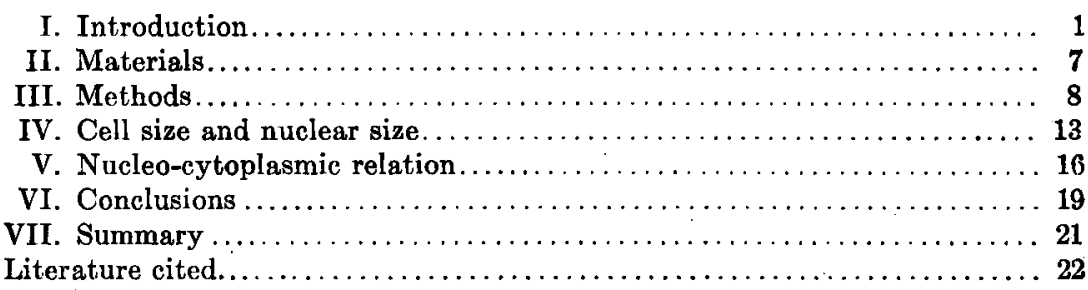

\section{INTRODUCTION}

The fundamental importance of the primary differentiation of protoplasm into cytoplasm and nucleus has naturally led to numerous studies, both morphological and physiological, on the interrelations of these parts of the cell complex. One trend of investigation has been to determine the absolute and relative size of nucleus and cytoplasm in different types of cells, and in similar cells under varying physiological conditions. Among the studies from this standpoint the following may be mentioned as pertinent to the problem in hand. Strasburger ('93) determined, by a series of careful measurements in embryonic stages of over forty species of plants, that there is quite a definite ratio between cell and nuclear size, and advanced the view that this is determined by the extent of the 'working sphere of the nucleus.' Gerassimoff ('02) concluded that cell size is determined by nuclear size, on the basis of the fact that when the daughter nuclei, 
at division stages of Spirogyra, are both retained in one of the daughter cells, that cell becomes unusually large. Boveri ('02, '05) found that the size of the nuclei of the cells of sea urchin larvae is directly proportional to the number of chromosomes which enter them, and that cells which contain small nuclei are below the normal size, because such cells divide more frequently than those with large nuclei.

In a number of publications, the earliest of which appeared in 1890, Minot advanced the view that differentiation, senescence and death are concomitant with, and the result of, an increase in the proportion of cytoplasm to nucleus in cells.

Minot holds that the egg, at the earliest stage of its development, is actually in a senile state in which there is an excessive amount of cytoplasm as compared with the nucleus. During the process of cleavage, however, this relation is reversed by a rapid increase in the nuclear material. Thus rejuvenation is brought about chiefly by the segmentation of the egg, and depends upon the increase of the nucleus; and senescence gradually appears as development proceeds on account of the increase of the cytoplasm which is necessary for the differentiation of the cells. He wrote ('97, p. 370):

The animal, when it is young, has cells with a small amount of protoplasm. . . . . In order that perfection of the adult structure should be attained, it is necessary that the mere undifferentiated cells, each with a small body of protoplasm, should acquire first an increased amount of protoplasm, and then from the increased protoplasm should be taken the material to result in differentiation, in specialization. . . . The increase of the protoplasm is . . . . the mark both of advancing organization and advancing age.

In regard to the lower forms Minot says:

If it be true that there is among Protozoa, among unicellular animals, anything comparable to the gradual decline in the growth power which occurs in us we shall expect it to be revealed in the condition of the cells-to see in those cells which are old an increase in the proportion of protoplasm, and consequently a diminution in the relative amount of nucleus (p. 515).

The interest in the relative amount of nuclear to cytoplasmic materials in cells has been largely augmented by the contributions 
of R. Hertwig and his school. As a result of his work on the conjugation of Infusoria, published in 1889, Hertwig has been led to attach great importance to what he terms the 'Kernplasmarelation.' In 1903 he discussed his theory and maintained that there exists for each type of cell a definite normal volume relation between nucleus and cytoplasm, and emphasized the fact that the normal relation may be disturbed by various environmental changes. More recently he has emphasized definite periodic changes of the Kernplasmarelation between successive cell divisions, the immediate cause of cell division being a state of cytoplasmic and nuclear tension (Kernplasma-Spannung) induced by an overgrowth of the nucleus, and the resolving of the single cell into two restores the functional Kernplasmarelation. Hertwig interprets the large nucleus of the immature egg as a sign of a state of depression, and nuclear reduction, which is accomplished by the phenomenon of maturation, and fertilization are followed by a period of rapid cell division resulting in the formation of the embryo. From the study of various Protozoa (Actinosphaerium, Paramaecium, Dileptus) he finds that senescence, 'depression' and 'physiological degeneration' are concomitant with great nuclear growth. For example, certain Infusoria, which have been supplied with a superabundance of food, show physiological degeneration which is characterized chiefly by a disproportionate development of the nucleus. A return to the normal condition of the cell is brought about by a direct elimination of the superfluous nuclear material, or, for example, by conjugation. "Die Befruchtung ist kein excitatorischer, sondern ein regulatorischer Vorgang."

It is unnecessary at this time to review the many papers which have recently appeared, under Hertwig's stimulus, on the effects of various internal and external conditions upon the Kernplasmarelation, or its finer analysis during the various phases of cell life. Popoff, for example, who has made some of the most important studies on the subject, found that in the infusorian Frontonia leucas immediately after division there is a decrease in the nucleus, which is followed by a slow growth (functional growth) and then by a rapid growth (divisional growth) of the nucleus 
which brings about again the Kernplasma-Spannung which is the inciting cause of the succeeding bipartition of the cell.

In a word, some investigations seem to show that there is for each kind of cell a characteristic size relation between nucleus and cytoplasm-variations from which lead to various phenomena, normal and abnormal. Minot holds that a decrease of nuclear as compared with cytoplasmic material leads to a slowing of the division rate, while Hertwig and his school believe that an increase of nuclear as compared with cytoplasmic material leads to a slowing of the rate of division.

Child ('10), from interesting experiments upon senescence and rejuvenescence in a planarian, puts emphasis on physiological rather than morphological factors as the fundamental cause of these phenomena.

senescence in nature consists physiologically in a decrease in the rate of metabolism and this is determined morphologically by the accumulations in the cells of structural obstacles to metabolism, e.g., decrease in permeability, increase in density, accumulation of relatively inactive substances, etc. Rejuvenescence consists physiologically in an increase in the rate of metabolism and is brought about in nature by the removal in one way or another of the structural obstacles to metabolism.

Conklin ('12) has recently extensively reviewed the subject of cell size and nuclear size on the basis of studies on gasteropods from the standpoint of cell-lineage, and he states:

My observations do not support the view that senescence is due to a decrease (Minot) or an increase (Hertwig) of nuclear, as compared with protoplasmic material; nor that rejuvenescence is accomplished during cleavage by the great increase of nuclear material relative to the protoplasm. On the other hand senescence seems to be associated with a decrease, rejuvenescence with an increase of metabolism (Child).

In a sense there are two aspects of the nucleo-cytoplasmic relation theory. One considers the nuclear-cytoplasmic relation during the various phases of the life of the individual cell and its fluctuations during vegetative and reproductive phases. The other takes into account the general nuclear-cytoplasmic relation which obtains in the various cell generations in the life history of an organism, all the cells of which are lineal descendants of a single cell-the fertilized egg (Metazoa) or exconjugant 
(Protozoa). It is the latter application of the nucleo-cytoplasmic relation theory which is considered in the present study.

The studies on pedigreed races of various Protozoa, under conditions in which occur, sooner or later, a gradual decline in the power of reproduction and finally death, have shown diverse results in regard to the absolute variations in size of the cells and their nuclei and also in regard to the relative changes in size of cytoplasm and nucleus during the various phases of reproductive activity.

For example, Maupas ('88) in his extensive studies on the life histories of various Infusoria found a decrease in size of the cells and an increase in the size of the nuclei as the organisms proceeded to what he termed 'senile degeneration.' Calkins ('02, '04) from studies on the life history of Paramnecium caudatum, in which he followed with great care several races of this species through a number of depression periods which finally culminated in death, stated that "The first clearly marked period of depression . . . . was characterized by a well-defined reduction in size (down to 109 microns), and by vacuolization of the endoplasm . . . . " ('04, p. 443). Concerning the animals in later periods of low fission rate he wrote: "These became smaller and smaller," and again: "These unstimulated individuals died out in about 508 generations after becoming much emaciated and reduced in size and with reduced nuclei" (p. 444).

Popoff ('07) in his study of the life history of Stylonychia mytilus and of Paramaecium caudatum clearly described and illustrated a marked decrease in size of the cells as degeneration proceeded and this was accompanied by a marked increase in size of the nuclei. Similarly, in his work on Frontonia leucas ('08) he found that slow division rate was accompanied by a decrease in cell size and increase in nuclear size. On the other hand, Woodruff ('05) found a marked increase in cell size as well as an increase in nuclear size during the life of a pedigreed race of Oxytricha fallax, ${ }^{1}$ and Gregory ('09) in her study of the

\footnotetext{
1 In the very last stage of degeneration, when the two or three remaining cells of the race were unable to divide at all, there was a marked shrinking before death occurred. This, obviously, has no bearing on the present problem.
} 
life history of Tillina magna found the largest cells when the division rate was lowest. But she noted that the nucleus may or may not increase in size during periods of low activity; "if an increase does take place it is generally found that the cytoplasmic material has increased also and the ratio between the two is the same as in the periods of high activity." Moody ('12) from measurements of cells from a pedigreed culture of Spathidium spathula found that:

When the division energy was low and the culture had already entered on a period of depression, both the coefficient and Kernplasmarelation indicate a decrease in nuclear volume, rather than the abnormal nuclear growth claimed by Popoff in 1908. Hertwig maintained that an increase in nuclear mass led to a slowing of the division rate

this is not true of Spathidium where a slow division rate is coincident with a decrease of nuclear material.

From the above-mentioned typical investigations, it is to be noted that those of Maupas, Calkins and Popoff showed a decrease in the size of the cell as physiological degeneration increased, while those of Woodruff and Gregory showed an increase in the size of the cell under similar conditions. The results of Calkins and Moody indicated a decrease in the size of the nucleus as physiological degeneration increased; those of Gregory showed no uniform increase or decrease under such conditions, while those of Woodruff and Popoff clearly indicated a marked increase in the size of the nucleus. From the standpoint of Hertwig's Kernplasmarelation theory: Maupas' and Popoff's results are affirmative; Gregory's and Moody's are negative; while the results of Calkins and of Woodruff give no data from which the proportion of cytoplasmic to nuclear material can be computed.

The present paper presents the results derived from a detailed. investigation of cell size, nuclear size and the nucleo-cytoplasmic relation during the life of one of the pedigreed races of Oxytricha fallax employed in my study published in 1905.

I have determined to make this intensive study of cell and nuclear size in this race of Oxytricha fallax for several reasons. First, in response to several requests for detailed information in regard to the proportion of cytoplasm to nucleus during the 
different phases of reproductive activity illustrated in my earlier paper. Second, because, on the basis of my microphotographs of a few specimens, some readers have determined (supposedly) that I found an increase in the proportion of nuclear to cytoplasmic material. And finally, because it appears to me that the study of the morphological changes which accompanied the protracted physiological degeneration of this culture offers a particularly favorable opportunity to determine exactly how great the variations in cell size and nuclear size are during the life of a race of Oxytricha and whether these variations are of such a character as to support either of the current morphological conceptions of cytoplasmic and nuclear relations with reference to physiological degeneration.

\section{MATERIALS}

This race of Oxytricha fallax is one of several cultures of hypotrichous Infusoria which I bred some ten years ago in Professor Calkins' laboratory at Columbia University. The chief object of the work at that time was to repeat some of the work of Maupas and to determine whether hypotrichous forms show cyclical changes in their vitality similar to those which Calkins had found to occur in his race of Paramaecium and, if such did occur, to endeavor to reinvigorate the organisms by artificial stimulation. The data at hand from this work led me to conclude that "the species studied pass through periods of greater or less general vitality as measured by the rate of division. This cyclical change is most prominent in the Oxytricha A culture." (The one under consideration in the present study.) "The periods of depression lead to death if the culture is subjected continuously to the same environment." (p. 626).

Subsequently I have reinvestigated the problem of the cyclical character of infusorian life history in Paramaecium with special reference to the effect of the environment (culture medium) and have secured results which, I believe, conclusively prove that this form, at least, has unlimited power of reproduction by division, under favorable environmental conditions, without conjuga- 
tion or artificial stimulation. This conclusion is based on the fact that $I$ have been able to breed a pedigreed race of Paramaecium aurelia for (so far) over six years or through more than 3800 generations without periods of physiological depression-the animals of the present generation being in as normal morphological and physiological condition as the specimen isolated to initiate the culture. It is apparent, however, that closely related species, and different races of the same species, are adapted to more or less diverse environmental conditions, and it is this factor which is undoubtedly at the foundation of the diverse results which have been obtained by various students of the longevity of infusoria in culture without conjugation (cf. Woodruff '11).

Therefore, in the light of studies during the past decade, I would interpret the cycle of my Oxytricha A culture as being the result of the fact that the race of Oxytricha fallax which was employed was not adapted to live indefinitely "when continuously subjected to the same environment" of hay infusion ('05, p. 627). I believe that if an entirely suitable environment had been secured this culture would have given evidence of unlimited power of reproduction by division without conjugation as my present $P$. aurelia race has done. In other words this culture of $O$. fallax affords detailed data in regard to the cytological changes which occur during a long period of gradual physiological degeneration induced by the environment, which should be of great value in determining variations in cell and nuclear size and also the Kernplasmarelation under such conditions.

\section{METHODS}

The methods employed in conducting the cultures of this race are stated in detail in the original paper and are similar to those which $I$ have subsequently used in all my pedigreed culture work. It is only necessary to repeat here that the culture was started by the isolation of a wild specimen on a depression slide in about five drops of hay infusion and when this animal by division had produced four individuals each of these was isolated to form one of the four lines of this culture, O. fallax A. These four lines 
were continued by the daily isolation of a specimen from each which was placed in fresh culture medium on a clean slide. The accompanying graph (fig. 1) shows the daily rate of division of all four lines averaged together and this again averaged for each ten-day period of the life of the culture.

Infusions of hay or grass were used to the exclusion of all other culture media except at certain periods of acute physiological depression. These exceptions are of no interest for the present problem because the animals preserved from such periods have been excluded from the series measured; for example during periods 21 and 22 when beef extract was employed in an endeavor to rejuvenate the race. The great rise in the rate of reproduction which occurred later was attributed to this temporary environmental change. The culture was subjected to the ordinary room temperatures throughout the work, but such variations as occurred are unimportant as the mean temperature during parts $A, B, C$ and $D$ is essentially the same and produces an error which is negligible, when the length of the periods and the number of specimens under consideration is taken into account.

As the present study is based entirely upon measurements of mounted specimens the following statement of the methods employed in preservation is important:

The specimen to be preserved is isolated by means of a fine-pointed pipet on a clean depression slide . . . . with as little of the culture medium as possible. To this is added three or four drops of bichlorid of mercury in saturated solution with 5 per cent of glacial acetic acid. After about five minutes the specimen is transferred to another slide and a few drops of 75 per cent alcohol is added. A slide is now smeared with a trace of egg-albumin and the specimen is taken from the 75 per cent alcohol and gently spurted onto the albumin. After a short time, when the alcohol has coagulated the albumin, the slide with the specimen adhering to it is transferred to a jar of 75 per cent alcohol and is thereafter treated by the ordinary slide method. For staining, Ranvier's picrocarmin was used . . . . Clearing was done with xylol, and damar was used in mounting.

All the specimens were fixed, stained and mounted in exactly the same way so that alterations due to shrinkage should be approximately the same. Some two hundred slides were made 


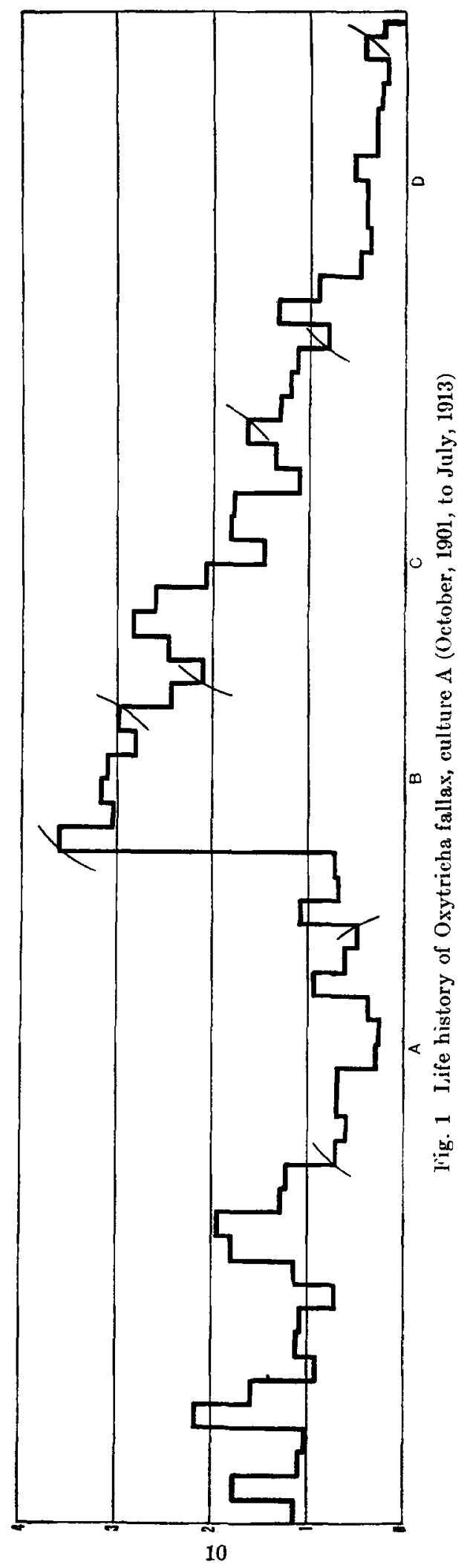


which comprise about seven hundred specimens. It is important to emphasize the fact that in the present study are considered specimens only from periods in which the regular culture medium was employed, and also those only from the direct lines of the culture. The specimens preserved from the stock cultures (i.e., mass cultures seeded from the main lines) have been omitted. This left over 450 specimens of the pedigreed race for measurement. These specimens cover nearly the entire range of the life of the race, but of necessity a majority are representatives of periods of comparatively high division rate (fig $1, B$ and $C$ ). The methods necessary for the breeding of pedigreed cultures make it impossible to kill and preserve a large number of specimens when the rate is low, because at such periods it is essential to keep alive all animals available to ensure the continuance of the strain. It is believed, however, that whatever may be lost in accuracy, by not having larger numbers to measure at certain depression periods, is far more than counterbalanced by the fact that the ancestry and the environmental conditions of those studied is accurately known.

It was apparent when the material was surveyed that it was impossible to secure measurements which would give accurately the volume of either cytoplasm or nucleus during the periods of marked physiological depression owing to the irregular contours of the cells and particularly of the nuclei. Accordingly, it was determined first to make accurate measurements of the areas of the cells and their nuclei throughout the entire life of the raceas only by this method could the size of the cell and nucleus during marked depression periods $(A, D)$ be compared with those during periods of comparatively high reproductive activity $(B, C)$.

Since from these data it was impossible to determine the relative volume of cytoplasm and nucleus at the different periods of the life history, it was decided to investigate this point with respect to the specimens from periods $B$ and $C$, during which the rates of division were characteristically different, while the form of the cells and their nuclei was sufficiently regular to permit the computation of their volumes from linear measurements. 
The first series of measurements, those of areas, were made with an ocular micrometer cross-ruled into squares. The areas of the cells and nuclei were each plotted twice to obviate errors as far as possible. The unit in which the areas are expressed in the tabulations equals 225 square microns. The second series of measurements were made with an ordinary ocular micrometer. The length and breadth of each cell was determined and also the length and breadth of each of the two macronuclei. It was impossible to measure the thickness of either the cell or nucleus, but from a series of observations it was apparent that the average thickness of the cell is very nearly one half that of the width and that the thickness of the macronucleus is the same as its width. ${ }^{2}$ Therefore these dimensions, which are without doubt substantially accurate and produce a negligible error, were employed for the third dimension. The results are expressed in cubic microns.

Throughout this study the term 'nucleus' has taken into account the macronuclei only and the micronuclei have been disregarded as in the investigations of former workers in this field. This is justifiable from several standpoints. In the first place the area and the volume of the micronuclei is insignificant in comparison with that of the macronuclei, and actual measurements fail to reveal variations which would appreciably affect the results. Second, variations in the number of micronuclei which were noted occurred characteristically during periods of marked physiological degeneration when it was impossible to compute the volumes of the parts of the cell (Periods $A$ and $D$ ), and when the macronuclear increase was so great that the micronuclear variations would not appreciably affect the area determinations. Third, it is well established that the macronucleus comprises the chromatin specialized for the general vegetative cell activities-and so is of paramount interest in the present connection.

2 It is apparent, of course, that since these hypotrichous forms are considerably flattened dorso-ventrally, the mounted specimens present to view either the dorsal or ventral side of the animal. 


\section{CELL SIZE AND NUCLEAR SIZE}

In order to analyze the data accurately four parts of the life of the race were selected, designated respectively $A, B, C$, and $D$, each of which comprises, as it were, a different phase of the reproductive activity. Part $A$ includes cells in which the rate of reproduction and general vitality is very low (less than one division in twenty-four hours); part $B$ includes cells in which the reproductive activity is actually and relatively very high (average about three divisions in twenty-four hours); part $C$ includes cells in which the reproductive activity is about 'normal', though considerably less than $B$ (average about two divisions in twentyfour hours); and part $D$ includes cells which have again reached a stage of marked morphological and physiological degeneration.

The data may be considered best in connection with the tables. Table 1 gives, for each of the twenty-one ten-day periods for

\begin{tabular}{|c|c|c|c|c|c|c|c|c|c|c|}
\hline \multirow[b]{2}{*}{ PART } & \multirow[b]{2}{*}{$\begin{array}{l}\text { NUMBER } \\
\text { OF } \\
\text { TEN-DAY } \\
\text { PERIOD }\end{array}$} & \multirow[b]{2}{*}{$\begin{array}{c}\text { NUMBER } \\
\text { OF } \\
\text { BPFCIMENS }\end{array}$} & \multicolumn{2}{|c|}{$\begin{array}{c}\text { GMALLEST } \\
\text { CELLL }\end{array}$} & \multicolumn{2}{|c|}{$\begin{array}{l}\text { SMALLEBT } \\
\text { NUCLEUS } \\
\end{array}$} & \multicolumn{2}{|c|}{$\begin{array}{c}\text { LARGERT } \\
\text { CELL }\end{array}$} & \multicolumn{2}{|c|}{$\begin{array}{l}\text { LARGEST } \\
\text { NUCLEUOS }\end{array}$} \\
\hline & & & 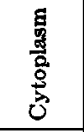 & $\begin{array}{l}\frac{\mathrm{g}}{\tilde{E}} \\
\frac{\mathrm{e}}{\mathrm{g}} \\
\mathrm{z}\end{array}$ & 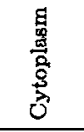 & 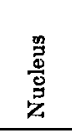 & 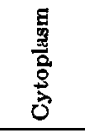 & 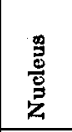 & 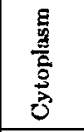 & 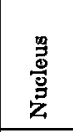 \\
\hline \multirow{4}{*}{ A. } & 16 & 3 & 16.25 & 2.75 & 24.65 & 1.50 & 24.65 & 1.50 & 16.25 & 2.75 \\
\hline & 18 & 3 & 10.72 & 1.52 & 15.65 & 1.44 & 17.28 & 1.80 & 17.28 & 1.80 \\
\hline & 24 & 4 & 10.75 & 1.72 & 10.75 & 1.72 & 16.00 & 2.75 & $\mid 13.75$ & 2.80 \\
\hline & 25 & 8 & 9.73 & 1.04 & 9.73 & 1.04 & 22.50 & 2.30 & 22.50 & 2.30 \\
\hline \multirow{6}{*}{ B } & 29 & 62 & 2.75 & 0.65 & 6.55 & 0.52 & 11.38 & 0.92 & 7.80 & 1.16 \\
\hline & 30 & 11 & 4.97 & 0.71 & 6.35 & 0.63 & 8.65 & 0.69 & 6.75 & 0.79 \\
\hline & 32 & 43 & 3.69 & 0.60 & 4.16 & 0.50 & 11.96 & 1.04 & 11.96 & 1.04 \\
\hline & 33 & 91 & 4.00 & 0.54 & 4.20 & 0.46 & 11.20 & 0.98 & $\mid 11.20$ & 0.98 \\
\hline & 34 & 37 & 4.00 & 0.70 & 5.73 & 0.48 & 12.18 & 1.04 & 12.18 & 1.04 \\
\hline & 36 & 63 & 5.76 & 0.80 & 11.50 & 0.72 & 13.50 & 1.44 & 13.50 & 1.44 \\
\hline & 37 & 53 & 8.44 & 0.84 & 8.81 & 0.60 & 18.40 & 1.44 & $\mid 18.40$ & 1.44 \\
\hline & 38 & 10 & 7.24 & 0.91 & 8.26 & 0.69 & 10.90 & 0.90 & 7.24 & 0.91 \\
\hline & 39 & 33 & 3.36 & 0.64 & 4.08 & 0.44 & 8.12 & 1.04 & 8.12 & 1.04 \\
\hline & 40 & 10 & 4.01 & 0.60 & 5.00 & 0.56 & 7.89 & 0.77 & 6.72 & 0.79 \\
\hline & 41 & 8 & 8.44 & 0.77 & 10.11 & 0.76 & 12.10 & 0.89 & 10.74 & 1.07 \\
\hline & 42 & 9 & 7.47 & 0.70 & 7.47 & 0.70 & 14.30 & 1.08 & \begin{tabular}{|l}
14.30 \\
\end{tabular} & 1.08 \\
\hline \multirow{5}{*}{ D. } & 50 & 2 & 8.95 & 0.70 & 8.95 & 0.70 & 11.00 & 1.20 & 11.00 & 1.20 \\
\hline & 51 & 7 & 8.36 & 0.72 & 10.42 & 0.68 & 11.21 & 0.84 & 11.21 & 0.84 \\
\hline & 52 & 1 & 11.70 & 0.76 & 11.70 & 0.76 & 11.70 & 0.76 & 11.70 & 0.76 \\
\hline & 56 & 1 & 11.16 & 1.20 & 11.16 & 1.20 & 11.16 & 1.20 & 11.16 & 1.20 \\
\hline & 62 & 2 & 12.53 & 1.62 & 12.53 & 1.62 & 14.07 & 1.68 & 14.07 & 1.68 \\
\hline
\end{tabular}


which comparable material was available, the area of the smallest cell and its nucleus, and of the largest cell and its nucleus and also the area of the smallest nucleus and its cell and of the largest nucleus and its cell. Table 2 gives in parallel columns for each part $(A, B, C$ and $D)$ of the life of the race: (1) the number of the ten-day period from which the specimens were taken, (2) the number of specimens measured in each ten-day period, (3) the range of cytoplasmic area during each ten-day period, (4) the mean of this range, (5) the range of nuclear area for each ten-day period, (6) the mean of this range. A further analysis of these data, in which the cells of each part $(A, B, C$ and $D)$ of the life of the race is taken as a unit, is given in table 3 .

From these data it is clear that, on the basis of measurements of area, and this is a sufficient criterion for the particular aspect of the question under immediate consideration, there is great variation in cell size during each period but that the mean size of the cell is greatest in part $A$ when the reproductive activity is low and least in part $B$ when the reproductivity activity is highest, and then becomes larger in parts $C$ and $D$ as the rate of reproduction gradually wanes. The data for the nuclear area also indicate that there is great variation in nuclear size during each period but that the mean size of the nucleus is greatest in part $A$ and smallest in part $B$, and is again larger in parts $C$ and D. The difference between the means of the cytoplasm and also of the nucleus in $C$ and $D$ is near the limits of the probable error of the determination so that it is not positively established that there is a real increase in size of the nucleus and cytoplasm during part $D$ as compared with part $C$. It is clear, however, that the mean size of the nucleus is smallest when the reproductive activity is greatest. It should be emphasized that the greatest difference in size of both cytoplasm and nucleus is seen in comparing $A$ and $B$-the periods which are characterized by the most marked change in divisional activity. It is apparent then, from measurements of the area of the cytoplasm and nucleus of cells of this race of Oxytricha that the mean size of both the cells and their nuclei is smallest at the period of greatest reproductive activity. 
TABLE 2

\begin{tabular}{|c|c|c|c|c|c|c|}
\hline \multirow{2}{*}{ PART } & \multirow{2}{*}{$\begin{array}{c}\text { NUMPER } \\
\text { OF } \\
\text { TEN-DAT } \\
\text { PERIOD }\end{array}$} & \multirow{2}{*}{$\begin{array}{c}\text { NOMBER } \\
\text { OF } \\
\text { SPECIMENS }\end{array}$} & \multicolumn{2}{|c|}{ CYTOPLASM } & \multicolumn{2}{|c|}{ NUCLETE } \\
\hline & & & Range & Mean & Range & Mean \\
\hline \multirow{4}{*}{$\mathbf{A}$} & 16 & 3 & $16.25-24.65$ & 19.86 & $1.50-2.75$ & 2.22 \\
\hline & 18 & 3 & $10.72-17.28$ & 11.21 & $1.44-1.80$ & 1.58 \\
\hline & 24 & 4 & $10.75-16.00$ & 13.87 & $1.72-2.80$ & 2.44 \\
\hline & 25 & 8 & $9.73-22.50$ & 15.28 & $1.04-2.30$ & 1.63 \\
\hline \multirow{6}{*}{ B. } & 29 & 62 & $2.75-11.38$ & 6.13 & $0.52-1.16$ & 0.72 \\
\hline & 30 & 11 & $4.97-8.65$ & 6.19 & $0.63-0.79$ & 0.70 \\
\hline & 32 & 43 & $3.69-11.96$ & 6.28 & $0.50-1.04$ & 0.71 \\
\hline & 33 & 91 & $4.00-11.20$ & 6.39 & $0.46-0.98$ & 0.65 \\
\hline & 34 & 37 & $4.00-12.18$ & 6.81 & $0.48-1.04$ & 0.78 \\
\hline & 36 & 63 & $5.76-13.50$ & 10.15 & $0.72-1.44$ & 1.03 \\
\hline \multirow{5}{*}{ C. } & 37 & 53 & $8.44-18.40$ & 11.73 & $0.60-1.44$ & 0.95 \\
\hline & 38 & 10 & $7.24-10.90$ & 8.83 & $0.69-0.91$ & 0.80 \\
\hline & 39 & 33 & $3.36-8.12$ & 4.91 & $0.44-1.04$ & 0.70 \\
\hline & 40 & 10 & $4.01-7.98$ & 6.06 & $0.56-0.79$ & 0.69 \\
\hline & 41 & 8 & $8.44-12.10$ & 10.61 & $0.76-1.07$ & 0.88 \\
\hline \multirow{6}{*}{ D. } & 42 & 9 & $7.47-14.30$ & 10.92 & $0.70-1.08$ & 0.90 \\
\hline & 50 & 2 & $8.95-11.00$ & 9.97 & $0.70-1.20$ & 0.95 \\
\hline & 51 & 7 & $8.36-11.21$ & 9.50 & $0.68-0.84$ & 0.73 \\
\hline & 52 & 1 & $11.70-11.70$ & 11.70 & $0.76-0.76$ & 076 \\
\hline & 56 & 1 & $11.16-11.16$ & 11.16 & $1.20-1.20$ & 1.20 \\
\hline & 62 & 2 & $12.53-14.07$ & 13.30 & $1.62-1.68$ & 1.65 \\
\hline
\end{tabular}

TABLE 3

Cytoplasm

\begin{tabular}{c|c|c|r|c|c}
\hline PART & $\begin{array}{c}\text { NUMBER } \\
\text { OF } \\
\text { SPECIMENS }\end{array}$ & R.ANGE & MEAN & $\begin{array}{c}\text { STANDARD DEVI- } \\
\text { ATION }\end{array}$ & $\begin{array}{c}\text { COEFfICIENT OF } \\
\text { VARIATION }\end{array}$ \\
\hline A..... & 18 & $9.73-24.65$ & $15.05 \pm 0.89$ & $3.80 \pm 0.42$ & $25.28 \pm 2.84$ \\
B..... & 244 & $2.75-12.18$ & $6.36 \pm 0.07$ & $1.70 \pm 0.05$ & $26.72 \pm 0.81$ \\
C...... & 186 & $3.36-18.40$ & $9.44 \pm 0.15$ & $3.18 \pm 0.11$ & $33.68 \pm 1.17$ \\
D..... & 13 & $8.36-14.07$ & $10.45 \pm 0.35$ & $1.89 \pm 0.25$ & $18.08 \pm 2.40$ \\
\hline
\end{tabular}

Nucleus

\begin{tabular}{r|r|l|l|l|l}
\hline A...... & 18 & $1.04-2.80$ & $1.90 \pm 0.08$ & $0.53 \pm 0.059$ & $27.89 \pm 3.13$ \\
B..... & 244 & $0.46-1.16$ & $0.70 \pm 0.006$ & $0.13 \pm 0.003$ & $18.57 \pm 0.57$ \\
C...... & 186 & $0.44-1.44$ & $0.90 \pm 0.009$ & $0.20 \pm 0.006$ & $22.22 \pm 0.78$ \\
D..... & 13 & $0.68-1.68$ & $0.94 \pm 0.06$ & $0.35 \pm 0.045$ & $37.23 \pm 4.93$ \\
\hline
\end{tabular}




\section{NUCLEO-CYTOPLASMIC RELATION}

In order to determine whether there is any characteristic change in the nucleo-cytoplasmic relation as the power of reproduction wanes, it was important to measure the volume of cytoplasm and nucleus. Here, for reasons already noted, it was necessary to confine the study to specimens from parts $B$ and $C$, but results from these cells should adequately answer the question. For this purpose 100 cells from $B$ and 100 cells from $C$ were measured. In $B$ the 244 available cells were distributed through ten-day periods, nos. 29, 30,32, 33 and 34 ; and in $C$ the 186 available cells were from ten-day periods no. 36 through no. 42 (fig. 1). The 100 cells in $B$ and the 100 cells in $C$ which were measured were taken proportionately from each of the ten-day periods on the basis of the total number available in each of these periods. The actual cells measured were taken at random and the data secured therefore should be entirely representative of the groups measured for areas and already described.

The data secured in regard to the volume of cytoplasm and nucleus are presented in tables 4 and 5 , from which it is apparent that, although there is great variation in cell and nuclear size during each period, the mean volume of the cytoplasm and also the mean volume of the nucleus is smaller in period $B$, during which the division rate was higher, than in period $C$ in which

\begin{tabular}{|c|c|c|c|c|c|c|c|}
\hline \multirow[b]{2}{*}{ 色 } & \multirow{2}{*}{ 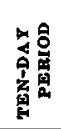 } & \multirow{2}{*}{ 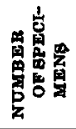 } & \multicolumn{2}{|c|}{ VOLUME OF CYTOPLASM } & \multicolumn{2}{|c|}{ VOLUME OF NUCLEUS } & \multirow{2}{*}{$\frac{C}{N}$} \\
\hline & & & Range & Mean & Range & Mean & \\
\hline \multirow{8}{*}{ B } & 29 & 25 & 2948.91-41563.36 & 17776.99 & $666.01-1884.96$ & 1009.26 & 16.61 \\
\hline & 30 & 5 & $11904.57-30159.36$ & 21328.85 & $913.15-1135.16$ & 983.03 & 20.63 \\
\hline & 32 & 18 & $7095.82-47048.60$ & 20572.81 & $660.01-1507.96$ & 1059.07 & 18.42 \\
\hline & 33 & 37 & $6588.98-33510.40$ & 16760.64 & $452.38-1478.64$ & 922.17 & 17.17 \\
\hline & 34 & 15 & $7602.67-21447.65$ & 14160.16 & $565.48-1545.66$ & 1004.81 & 13.09 \\
\hline & 36 & 34 & $12990.24-42101.62$ & 26709.61 & $995.88-2314.28$ & 1404.80 & 18.01 \\
\hline & 37 & 28 & $21790.13-62832.00$ & 39658.80 & $678.58-2408.56$ & 1525.94 & 24.98 \\
\hline & 38 & 5 & $15551.02-26464.83$ & 21269.26 & $522.64-1206.36$ & 737.86 & 27.82 \\
\hline \multirow[t]{4}{*}{ C } & 39 & 18 & $3901.86-18765.82$ & 9811.07 & $343.47-1234.64$ & 811.97 & 10.46 \\
\hline & 40 & $\mathbf{5}$ & $9047.90-24950.58$ & 13238.30 & $527.78-1005.30$ & 788.32 & 15.79 \\
\hline & 41 & $\mathbf{5}$ & $21184.85-39885.75$ & 32080.75 & $867.07-1373.92$ & 1118.39 & 27.68 \\
\hline & 42 & 5 & $20357.66-44635.86$ & 34346.28 & $800.05-2094.40$ & 1451.83 & 22.65 \\
\hline
\end{tabular}


TABLE 5

\begin{tabular}{|c|c|c|c|c|c|}
\hline \multirow[b]{2}{*}{ A } & \multicolumn{2}{|c|}{ VOZTAE OF CYTOPLAGM } & \multirow{2}{*}{ BTANDARD DEVIATION } & \multirow{2}{*}{$\begin{array}{l}\text { COEFFICIENT OF } \\
\text { VARIATION }\end{array}$} & \multirow{2}{*}{$\frac{C}{N}$} \\
\hline & Rango & Mean & & & \\
\hline B & $6588.98-47048.60$ & $17539.26 \pm 600.46$ & $8902.34 \pm 424.59$ & $50.75 \pm 2.41$ & \\
\hline \multirow[t]{2}{*}{$\mathrm{C}$} & $3901.86-62832.00$ & $26908.45=945.53$ & $14018.35 \pm 668.59$ & $52.09 \pm 2.48$ & \\
\hline & \multicolumn{2}{|c|}{ YOLUME OF NUCLEUB } & & & \\
\hline B & $452.38-1884.96$ & $984.17 \pm 17.00$ & $252.12 \pm 12.02$ & $25.61 \pm 1.22$ & 16.82 \\
\hline $\mathrm{C}$ & $343.47-2408.56$ & $1255.87 \pm 31.18$ & $462.40=22.05$ & $36.81 \pm 1.85$ & 20.42 \\
\hline
\end{tabular}

the rate was lower. Thus measurements of volume substantiate those already presented for areas.

The data now in hand (table 5) show that the increment of mean volume of cytoplasm in period $C$ (as compared with period $B$ ) is greater than that of the nucleus, as the nucleo-cytoplasmic relation in period $B$ is $1: 16.82$, while in period $C$ it is $1: 20.42$. Therefore the measurement of the cells of this race indicate that as the power of reproduction wanes the mean proportion of nuclear to cytoplasmic material becomes lower, owing to greater growth of the cytoplasm than of the nucleus, although individual cells show a wide variation at all periods of the life of the race.

In the above discussion the terms 'cytoplasm' and 'nucleus' have been employed to include these regions of the cell as usually defined. It is important, however, to consider the more obvious changes in the morphological condition of these elements during the life of the race. During part $B$ both cytoplasm and nucleus showed the normal, comparatively homogenous appearance. But beginning with ten-day period 36 , part $C$, about the $512 \mathrm{~d}$ generation, "the cytoplasm showed signs of vacuolization, and this increases steadily and at approximately the 600th generation (ten-day period 38) the nuclear apparatus begins to depart from the normal." These changes are very slight, though progressive, as we pass from the early to the latter part of $\mathrm{C}$, but during part $D$ "the cytoplasm is greatly vacuolated, the ventral cirri reduced, the macronuclei distorted and fragmented and the micronuclei increased beyond the typical number; a condition closely similar to that which obtained at the 230th generation" 
(ten-day period 24, part $A$ ). This vacuolization of cytoplasm and nucleus is not peculiar to the race of Oxytricha under observation, as similar phenomena are mentioned by other students of the life history of Infusoria.

Conklin ('12) first called attention to one aspect of this question:

Neither Minot nor Hertwig took account of the fact that a large part of the nuclear content belongs to both nucleus and protoplasm. The Kernplasmarelation depends very largely upon the quantity of protoplasmic material temporarily in the nucleus. . . . Neither of the authors named, in describing the enormous growth of the nuclear material during cleavage, took account of the growth of the protoplasm during cleavage at the expense of the yolk.

This, it seems to me, emphasizes a fundamental difficulty in many studies on the nucleo-cytoplasmic relation, and one which, in somewhat different aspect, has to be considered in the present work. The vacuolization of cytoplasm and nucleus in all probability does not represent strictly a reversible interchange of material between these two elements of the cell, but it certainly indicates a dilution of the fundamental constituents of the cytoplasm and nucleus (employing these terms in their usual sense) and, insofar as this is true may, and undoubtedly does, alter the proportion.

The question of importance, then, is whether the increase in size of cytoplasm and nucleus, and the decrease in the relative amount of nuclear to cytoplasmic material, which has been shown to occur in this race with declining reproductive activity (periods $C$ and $D$ ), indicates an actual change in these elements or whether the vacuolization is sufficient substantially to alter the results. A careful study of the cells with this in mind shows unmistakably that the cytoplasm and the nucleus, in the strictest interpretations of these terms, actually increase in volume with decreased fission rate. The mean difference in nuclear size and cell size between periods $A$ and $B$, and $B$ and $C$ are of such a magnitude as to be clearly beyond any error due to vacuolization. Careful study also shows that the vacuolization which is present in part $C$ is not sufficiently extensive appreciably to affect the nucleo-cytoplasmic relation. 


\section{CONCLUSIONS}

The results presented are suggestive from several points of view. The recent extensive and thorough work of Jennings on Paramaecium shows clearly that a wild population of either of the common species, aurelia or caudatum, can be resolved into several diverse races or genotypes which are distinguished by differences in size, and that these differences are independent of environmental factors. In other words, the various races maintain their relative sizes when bred under diverse conditions, provided only that the conditions are identical for each race. The present data bear directly on this problem in that they indicate the wide range of variation in size which may occur at the same and at different periods of the life of a pure line of Oxytricha, and emphasize the fact that even extreme variations in size are of little or no specific value, and that very large numbers of cells of a pure line under identical culture conditions and at the same division rate must be measured in order to establish morphological criteria of infusorian genotypes. In diverse races, the division rate of which is different under identical environmental conditions, the investigation is obviously still more difficult.

Although most studies on pedigreed races of Protozoa indicate that cell size decreases as the rate of division decreases, it is usually held, from studies in embryology, that cells which divide infrequently are larger, all things being equal, than those which divide more often. For example, Conklin has shown that the 'turret' cells of Crepidula are the smallest cells in the entire embryo when they are formed but since they divide only twice during the whole cleavage process they grow very large, whereas the cells from which they are derived, the apical cells, give rise during the same period to twelve cells whose combined volume is not much greater than the volume of one full-grown 'turret' cell. This is in accord with the present observations on Oxytricha and those of Gregory on Tillina magna.

It seems clear from my data that neither the size of the cell nor the size of the nucleus is the inciting cause of division, but rather that the rate of cell division is probably indirectly responsible for the size of the cell and the nucleus. The wide varia- 
tion in size during each period clearly indicates that the cell may function normally in diverse size relations (parts $B$ and $C$ ), and that the inciting cause of cell division must be sought in other factors. The fact that cells of a protozoan genotype show great size differences which bear no direct relation to division is of great significance as it indicates clearly that the conditions which induce growth may be distinguished from those which incite fission.

The data presented also indicate that the mean proportion of nuclear to cytoplasmic material is smaller as the rate of reproduction wanes $(B$ and $C$ ) and thus are in agreement with those of Moody's study of Spathidium. This result is contrary to the observations of Hertwig and his school though it is, at first glance, in agreement with Minot's nucleo-cytoplasmic conception of cytomorphic changes leading to senility. But Minot's theory, if I interpret it correctly, does not include cases of physiological degeneration other than those brought about by an inherent tendency to 'grow old,' and consequently, since the present data concerns cells which are degenerating as a result of their environment, the results only indirectly bear on his theory.

When we survey the results of the already numerous investigations on cell size and nuclear size and their relation to each other in the cell complex, one cannot fail to be impressed with the fact that the data are remarkably diverse and contradictory -much more so than would, a priori, be anticipated if the Kernplasmarelation idea were substantially sound. To cite but a single instance, the results of Popoff on Stylonychia mytilus and my own on Oxytricha fallax may be considered. These two races of closely related hypotrichous ciliates were bred under condition"s which should render them directly comparable, and each ended with the extinction of the lines after a considerable number of generations. Yet the cytoplasmic change in Stylonychia consisted in an unmistakable decrease as the division rate decreased, while that of Oxytricha showed an equally marked increase as the rate of division waned. In each there was nuclear enlargement with falling divisional activity-but obviously the decreased cytoplasm resulted in an increase in the proportion 
of nucleus to cytoplasm in Stylonychia, while the increase of both cytoplasm and nucleus in Oxytricha resulted (as we have seen) in a decrease in the proportion of nucleus to cytoplasm, owing to the slightly smaller increment of the nucleus as compared with that of the cytoplasm.

It cannot be doubted that the relative volume of cytoplasm and nucleus plays an important part in the life of every cell and that inconceivably small variations may, and probably do, produce far reaching disturbances many of which are not detectable. Likewise, I believe, it is a priori beyond the limits of probability that significant morphological changes would be as a rule of such a magnitude as to be measurable. Undoubtedly a morphological basis should be sought for the various physiological manifestations in degenerating cells, but, I believe, that the results so far at hand indicate that it is prejudging the problem and attempting to reduce it to unduly simple terms, when mere measurable mass relations are estimated as fundamental criteria.

My results with various cultures of Protozoa lead me to agree with the view that senescence seems to be associated with decreased metabolism and rejuvenescence with increased metabolism, but I am unable to correlate with these physiological factors any constant morphological changes such as the current nucleo-cytoplasmic relation theories demand.

\section{SUMMARY}

1. A wide variation in the size of the cells and of the nuclei occurs at all periods of the life of the race.

2. The mean size of the cell is smallest at periods of high reproductive activitity and becomes progressively larger as the division rate falls.

3. The mean size of the nucleus is smallest at periods of high reproductive activity and becomes progressively larger as the division rate falls.

4. The nucleo-cytoplasmic relation of individual cells shows a wide variation at all periods of the life of the race.

5. The mean proportion of nuclear to cytoplasmic material is highest during the period of greatest reproductive activity. 
6. The size of the cell and the size of the nucleus as well as the nucleo-cytoplasmic relation are interpreted as an incidental result rather than as a cause of the rate of cell division.

\section{LITERA'TURE CI'TED}

Calkins, G. N. 1902 Studies on the life history of Protozoa. The life cycle of Paramaecium caudatum. Arch. f. Entw. Mech., Bd. 15.

1904 Studies on the life history of Protozoa. Death of the $A$ series. Conclusions. Jour. Exp. Zoöl., vol. 1.

CHILd, C. M. 1910 A study of senescence and rejuvenescence based on experiments with Planaria dorotocephala. Arch. f. Entw. Mech., Bd. 31.

Conxuin, E. G. 1912 Cell size and nuclear size. Jour. Exp. Zoöl., vol. 12.

ErdmanN, R. 1912 Quantitative Analyse der Zellbestandteile bei normalem, experimentell verändertem und pathologischem Wachstum. Ergebnisse d. Anat. und Entwick., Bd. 20.

Gerassimoff, J. 1902 Die Abhängigkeit der Grösse der Zelle von Menge ihrer Kernmasse. Zeit. f. allgem. Physiol., Bd. 1.

Gregory, Louise H. 1909 Observations on the life history of Tillina magna. Journ, Exp. Zoöl., vol. 6.

HeRTwIG, R. 1889 Ueber die Kernkonjugation der Infusorien. Abh. Bayer, Akad. Wiss. Bd. 17.

1903 Ueber Korrelation von Zell-und Kerngrösse und ihre Bedeutung für die geschlechtliche Differenzierung und die Teilung der Zelle. Biol. Centralb., Bd. 23.

1908 Ueber neue Probleme der Zellenlehre. Arch. f. Zellforschung, Bd. 1.

MaUpas, E. 1888 Recherches expérimentales sur la multiplication des Infusoires ciliés. Arch. de Zoöl. expér. et gén., 2me ser., tom. 6.

Minot, C. S. 1890 On certain phenomena of growing old. Proc. Amer. Assn. Adv. Sci., vol. 29.

1907 Age, growth and death. Popular Sci. Monthly, vol. 71.

Moody, JUlia E. 1912 Observations on the life history of two rare ciliates, Spathidium spathula and Actinobolus radians. Jour. Morph., vol. 23.

Poporf, M. 1907 Depression der Protozoenzelle und der Geschlechtszelle der Metazoen. Arch. f. Protistenk., Bd. 1.

1908 Experimentelle cytologische Studien. Arch. f. Zellforschung. Bd. 1.

Strasburger, E. 1893 Ueber die Wirkungsphäre der Kerne und die Zellgrösse. Histol. Beiträge, Bd. 5.

Woodrurs, L. L. 1905 An experimental study on the life history of hypotrichous Infusoria. Jour. Exp. Zoöl., vol. 2.

1911 Evidence on the adaptation of paramaecia to different environments. Biol. Bulletin, vol. 22.

1913 Dreitausend und dreihundert Generationen von Paramaecium ohne Konjugation oder künstliche Reizung. Biol. Centralblatt, Bd. 33. 